\title{
GENERALIZED FURUTA INEQUALITY IN BANACH $*$-ALGEBRAS AND ITS APPLICATIONS
}

\author{
TAKAYUKI FURUTA
}

Abstract. Okayasu [12] proved the useful Löwner-Heinz inequality in Banach $*$-algebra as follows. Let $A$ be a unital hermitian Banach $*$-algebra with continuous involution and $a, b \in A$. If $a \geqslant b>0$, then $a^{p} \geqslant b^{p}$ for $p \in(0,1]$. For $a>0, a^{\alpha}=\exp (\alpha \log a)$, where $\log$ is the principal branch of the complex logarithm. As a nice application of this result, K.Tanahashi and M.Uchiyama [15] proved the following very interesting inequality. Let $a, b \in A$. Let $R \ni p, q, r \geqslant 0$ satisfy $(1+r) q \geqslant p+r$ and $q \geqslant 1$.

$$
\left(b^{\frac{r}{2}} a^{p} b^{\frac{r}{2}}\right)^{\frac{1}{q}} \geqslant\left(b^{\frac{r}{2}} b^{p} b^{\frac{r}{2}}\right)^{\frac{1}{q}} \quad \text { if } a \geqslant b>0 .
$$

This inequality may be called to be "Banach $*$-algebra version" of Furuta inequality. By using this result and Löwner-Heinz inequality in Banach $*$-algebra in Okayasu [12], we show the following generalized Furuta inequality. Let $a, b \in A$. If $a \geqslant b>0$, then for each $1 \geqslant q \geqslant t \geqslant 0$ and $p \geqslant q$

$$
a^{q-t+r} \geqslant\left\{a^{\frac{r}{2}}\left(a^{\frac{-t}{2}} b^{p} a^{\frac{-t}{2}}\right)^{s} a^{\frac{r}{2}}\right\}^{\frac{q-t+r}{(p-t) s+r}}
$$

holds for $s \geqslant 1$ and $r \geqslant t$. Moreover as an application of this inequality, we show that if $a \geqslant b>0$, for each $t \in[0,1], q \geqslant 0$ and $p \geqslant t$,

$$
G_{p, q, t}(a, b, r, s)=a^{\frac{-r}{2}}\left\{a^{\frac{r}{2}}\left(a^{\frac{-t}{2}} b^{p} a^{\frac{-t}{2}}\right)^{s} a^{\frac{r}{2}}\right\}^{\frac{q-t+r}{(p-t) s+r}} a^{\frac{-r}{2}}
$$

is decreasing for $r \geqslant t$ and $s \geqslant 1$ such that $(p-t) s \geqslant q-t$.

Mathematics subject classification (1991): 47A63, 47A05, 47C10.

Key words and phrases: Löwner-Heinz inequality, Furuta inequality, Banach $*$-algebra.

\section{REFERENCES}

[1] T. ANDO AND F. HiaI, Log-majorization and complementary Golden-Thompson type inequalities, Linear Alg. and Its Appl. 197, 198 (1994), 113-131.

[2] M. FuJII, Furuta's inequality and its mean theoretic approach, J. Operator Theory 23 (1990), 67-72.

[3] M. FuJII AND E. KAMEI, Mean theoretic approach to the grand Furuta inequality, Proc. Amer. Math. Soc. 124 (1996), 2751-2756.

[4] T. FurutA, $A \geqslant B \geqslant 0$ assures $\left(B^{r} A^{p} B^{r}\right)^{1 / q} \geqslant B^{(p+2 r) / q}$ for $r \geqslant 0, p \geqslant 0, q \geqslant 1$ with $(1+2 r) q \geqslant p+2 r$, Proc. Amer. Math. Soc. 101 (1987), 85-88.

[5] T. FURUTA, Elementary proof of an order preserving inequality, Proc. Japan Acad. 65 (1989), 126.

[6] T. FuRUTA, Extension of the Furuta inequality and Ando-Hiai log-majorization, Linear Alg. and Its Appl. 219 (1995), 139-155.

[7] T. FURUTA, T. YAMAZAKI AND M. YANAGIDA, Operator functions implying generalized Furuta inequality, Mathematical Inequality and Applications 1 (1998), 123-130.

[8] T. FuRUTA, T. YAMAZAKI AND M. YANAGIDA, Order preserving operator inequalities via Furuta inequality, to appear in Math. Japon. 
[9] E. HEINZ, Beiträge zur Störungstheorie der Spektralzerlegung, Math. Ann. 123 (1951), 415-438.

[10] E. KAMEI, A satellite to Furuta's inequality, Math. Japon 33 (1988), 883-886.

[11] K. LÖWNER, Über monotone Matrixfunktionen, Math. Z. 38 (1934), 177-216.

[12] T. OKAYASU, The Löwner-Heinz inequality in Banach *-algebra, to appear in Glasgow Math. J.

[13] K. Tanahashi, Best possibility of the Furuta inequality, Proc. Amer. Math. Soc. 124 (1996), 141-146.

[14] K. TANAHASHI, The best possibility of the grand Furuta inequality, to appear in Proc. Amer. Math. Soc.

[15] K. TANAhashi AND A. UchiYAma, The Furuta inequality in Banach *-algebra, to appear in Proc. Amer. Math. Soc. 